\title{
Fragmentation and Wage Inequality: Insights from a Simple Model
}

\author{
Juan CARLUCCIO \\ Banque de France and University of Surrey
}

\author{
Ivar EKELAND \\ CEREMADE and Chaire \\ "Finance et Développement Durable", \\ Université Paris-Dauphine
}

\author{
Roger GUESNERIE \\ Collège de France and Paris School of Economics
}

\begin{abstract}
We develop a simple model to study how globalization affects wage inequalities. The model features three goods, one is an "international" good, and two are local non-tradable goods. The non-tradable goods are produced by local labor, either skilled or unskilled, while labor of all types and all origins contribute to the production of the international good. We find that increasing participation of the South in global production and consumption lead to an increase in wage inequalities in the North. Higher South integration into global value chains reduces North-South wage inequalities.*
\end{abstract}

\section{Introduction}

One of the hottest debates on the effects of the present so-called globalization concerns its consequences for income inequality, both between nations and within nations. Bourguignon, F., and R. Guesnerie [1996] asked whether globalization decreases inequalities between nations while increasing inequalities within nations, in line with the questions feeding the titles of the articles of FreEman, R. [1995], Rodrik, D. [1997] or more recently Ebenstein, A., A. Harrison, and M. Mc Millan [2014]. The present paper attempts to shed light on the issue from a partial and in a sense naive viewpoint. The viewpoint is partial since the paper voluntarily leaves aside the questions associated either with capital accumulation or technical progress, whose distributional dimension has raised a lot of recent debates and controversies. It is also naive, in the sense that it provides a simplistic image of international trade which, although referring to the simplest version of the Heckscher-Ohlin model which has come to dominate trade modelling after the 19th century episode of globalization, attempts to depart as much as possible from its defining features. In the Heckscher-Ohlin story, international trade concerns goods produced from immobile local factors. In our model, besides local

*JEL: F62, F16, F23 / KEY WORDS: Fragmentation of Production, Globalization, Wage Inequalities. 
non-traded goods, there is a single international good which is internationally produced from all local factors and consumed in everywhere. Naturally, this model captures an extreme form of trade which extrapolates from the present trend associated with the continuous increasing role of multinational firms. It echoes the idea that the production of manufactures is associated with a "global value chain", which in this model is an aggregate of the global value chains of many specific manufactured goods (see Timmer, M., et al. [2014]). Finally, for the sake of simplicity, our world has two blocks, or regions, metaphorically the North and the South, echoing again the prospects of Timmer, M., et al.

Let us sum up. Our world has three goods: the international good produced "nowhere", and the two local non-traded goods. The non-traded goods are produced from local labor, either skilled or unskilled, while labor of all types and all origins contribute to the production of the international good. The paper aims at providing a clear understanding of the forces shaping inequalities between the North and the South, as well as between workers of different skills in the North, in the admittedly simplistic world under consideration. Most forms of globalization that we consider lead to an increase in wage inequalities in the North, while improving the wage of South's unskilled workers. We complement the theoretical analysis with a simple numerical simulation of our model. It aims at capturing an operationally more plausible image of the world under scrutiny, while stressing what we believe to be reasonable interpretations of the theoretical insights.

Our paper contributes to a burgeoning literature analysing global values chains and offshoring, of which closer to our work is AcEmoglu, D., et al. [2015]. Our approach is not in opposition, but rather attempts to provide a complementary view, to papers modelling offshoring and international production in Heckscher-Ohlin frameworks, where visible contributions include Helpman, E. [1984] and Grossman, G., and E. Rossi-Hansberg [2008]..$^{1}$

How does this paper relate to Malinvaud's scientific work? Let us remind the division of labor promoted by the Econometric Society: theory leaning on appropriate modelling on the one hand, empirical analysis relying on statistical examination of existing data on the other hand. Clearly, Malinvaud was one of the few people of his generation able to undertake frontier research on each side of the line. Our paper, even if we sketch at the end a quantitative illustration of the model under scrutiny, is clearly on one side of the dividing line. It goes without saying that our subject has no close connections with a number of subjects which were behind E. Malinvaud's theoretical work, and does not concern, to take some examples, either intertemporal equilibrium, (MaLinvaud, E. [1953]) or planning. Our preocupations however echo a constant interest of Malinvaud, as a professional economist as well as a policy adviser, for wages and income distribution problems.

1. In recent work, CARLuCCio, J., et al. [2016] modify the factor-proportions model to include trade in inputs and heterogeneous firms. For a variety of views of globalization, see e.g. Broda, C., J. Greenfield, and D. Weinstein [2006], Costinot, A., and J. Vogel [2010], Thoenig, M., and T. Verdier [2003]. 
Indeed, the labor market is the explicit subject of a number of his contributions (Malinvaud, E. [1980], [1983], [1984], [1994]) and a key implicit question behind his investigations in the economics of fixed prices and macroeconomics (Malinvaud, E. [1981 et 1982], [1991]), or even growth (Malinvaud, E. [1986], [1987]). And in a sense our text attempts to shed some different light on the functioning of labor markets in the new context of globalization.

We proceed in a standard way: we present the model in SECTION II, provide the equilibrium analysis in SECTION III, discuss the comparative statics analysis in SECTION IV and provide a simple numerical simulation in Section V. Section VI concludes.

\section{Model Setup}

The world is divided in two countries, the richer one, called North, and the poorer one, called South, with different types of labor as factors of production. All variables pertaining to North are denoted in capitals, and all variables pertaining to South in lower-case.

In North, there are $H$ skilled workers and $L$ unskilled workers. In South, there are no skilled workers and $\ell$ unskilled workers. Labor is perfectly mobile across sectors within countries, but immobile across borders. Labor markets are perfectly competitive. Wages $\left(W_{H}, W_{L}, w\right)$ will be determined in equilibrium.

There are three goods. Two of them are local (non-tradable) goods: one is produced and consumed in the North and the other is produced and consumed in the South. The third one is an industrial good $I$, consumed in both countries and produced by combining labor from both countries. The production of good $I$ can be thought of taking place "nowhere" or "in the air", capturing the idea that the disintegration of production across borders that happens within global value chains implies goods are "made in the world"2. There is perfect competition in all goods' markets.

\section{II.1. Preferences}

All inhabitants of North and all inhabitants of South have Cobb-Douglas utility. Respectively:

- $U\left(X_{0}, X_{I}\right)=X_{0}^{1-\alpha} X_{I}^{\alpha}$ in North

- $u\left(x_{0}, x_{I}\right)=x_{0}^{1-\beta} x_{I}^{\beta}$ in South

2. “...More and more firms now organize production on a global scale and choose to offshore parts, components or services to producers in foreign and often distant countries. The typical 'Made in' labels in manufactured goods have become archaic symbols of an old era. These days, most goods are 'Made in the World"”. (AnTràs, P. [2016], Ch. 1 p. 4) 
where the subscript 0 refers to the non-tradable goods and the subscript 1 refers to the industrial good. Notice that we allow the preference parameters $\alpha$ and $\beta$ to be potentially different. This admittedly ad-hoc formulation will allow us to study how changes in consumption patterns that can be associated with global economic integration affect wages in both locations.

\section{II.2. Production}

Denote by $H_{I}$ and $L_{I}$, respectively, the quantity of skilled and unskilled labor from North allocated to the production of the industrial good, and by $\ell_{I}$ the quantity of unskilled workers from South allocated to the production of the industrial good. Similarly, $\left(H_{0}, L_{0}\right)$ and $\ell_{0}$ denote the quantity of workers allocated to the production of the local good in each country.

The production functions are the following.

For the international good $I$ :

$$
Q_{I}=\left(\mu \ell_{I}^{\gamma}+(1-\mu) L_{I}^{\gamma}\right)^{\delta / \gamma} H_{I}^{1-\delta} \quad \text { with } \quad 0 \leq \mu \leq 1
$$

The expression $\frac{1}{1-\gamma}$ measures the elasticity of substitution between North's and South's unskilled labor. ${ }^{3}$ It varies from 1 to infinity when $\gamma$ goes from 0 to 1 . The coefficient $\mu$ measures some kind of relative weight of the North and the South labor in the production of the industrial good. There are different possible explanations for the existence of this relative weight (productivity or implicit embedded capital differences of the North and South labor inputs) and we will come back to them later. Note that the production of our industrial good is "fragmented", to use a word of the policy debate, and that that fragmentation, whatever the precise meaning, will intuitively increase with $\mu$ and $\gamma$, everything else being kept equal.

For the local good in the North, we assume a Cobb-Douglas production function ${ }^{4}$ :

$$
Q_{0}=H_{0}^{\theta} L_{0}^{1-\theta} \text { with } \quad 0<\theta<1
$$

For the local good in the South: $q=\ell_{0}$.

3. Note that when $\gamma$ goes to zero, we get Cobb-Douglas production functions (elasticity of substitution equal to 1):

$$
\lim _{\gamma \rightarrow 0}\left(\mu \ell_{I}^{\gamma}+(1-\mu) L_{I}^{\gamma}\right)^{\delta / \gamma} H_{I}^{1-\delta}=\ell_{I}^{\mu \delta} L_{I}^{(1-\mu) \delta} H_{I}^{1-\delta} .
$$

4. As in the case described in footnote 3, this function obtains in the limit when $\rho \rightarrow 0$ of $\left(\theta H_{0}^{\rho}+(1-\theta) L_{0}^{\rho}\right)^{1 / \rho}=H_{0}^{\theta} L_{0}^{1-\theta}$. In a previous version, we have worked with this general form, obtaining similar results. We choose a Cobb-Douglas formulation here to ease the exposition. 


\section{II.3. Labor Market Clearing Conditions}

The balance equations for the labor force are:

- Skilled workers in North: $H=H_{0}+H_{I}$

- Unskilled workers in North: $L=L_{0}+L_{I}$

- Unskilled workers in South: $\ell=\ell_{0}+\ell_{I}$

\section{II.4. Cost-Minimizing Input Choices}

The quantity of each type of labor allocated to each good is determined following a cost-minimization process. Absolute wages are denoted by $\left(W_{L}, W_{H}, w\right)$. It will prove useful to work with relative wages of northern to southern workers, which are defined as:

$$
\frac{W_{L}}{w}=w_{L}, \frac{W_{H}}{w}=w_{H} .
$$

The next Lemma reflects the input choices made for the production of the international good, as functions of the prices of the North's skilled and unskilled labor, and of the South's (unskilled) labor.

Lemma 1. The cost-minimizing inputs for the production of one unit of industrial good, are:

$$
\begin{aligned}
& \bar{\ell}_{I}=\mu^{-\delta / \gamma}\left(\frac{1-\delta}{\delta}\right)^{-1+\delta}\left(1+\left(\frac{1-\mu}{\mu}\right)^{\frac{1}{1-\gamma}} w_{L}^{\left.-\frac{\gamma}{1-\gamma}\right)^{-1+\delta-\delta / \gamma}} w_{H}^{1-\delta}\right. \\
& \bar{L}_{I}=\left(\frac{\mu}{1-\mu}\right)^{-\frac{1}{1-\gamma}} \mu^{-\delta / \gamma}\left(\frac{1-\delta}{\delta}\right)^{-1+\delta}\left(1+\left(\frac{1-\mu}{\mu}\right)^{\frac{1}{1-\gamma}} w_{L}^{-\frac{\gamma}{1-\gamma}}\right)^{-1+\delta-\delta / \gamma} w_{H}^{1-\delta} w_{L}^{-\frac{1}{1-\gamma}} \\
& \bar{H}_{I}=\left(\frac{1-\delta}{\delta}\right)^{\delta} \mu^{-\delta / \gamma}\left(1+\left(\frac{1-\mu}{\mu}\right)^{\frac{1}{1-\gamma}} w_{L}^{-\frac{\gamma}{1-\gamma}}\right)^{\delta-\delta / \gamma} w_{H}^{-\delta}
\end{aligned}
$$

Proof. See the Appendix.

The derivation of the unit cost functions for the two local goods is straightforward. We present the three unit cost functions in the following Lemma: 
Lemma 2. The unit costs functions are:

- For the international good I :

$$
C_{I}=\frac{1}{(1-\delta)^{1-\delta} \delta^{\delta}} \mu^{-\delta / \gamma}\left(1+\left(\frac{1-\mu}{\mu}\right)^{\frac{1}{1-\gamma}} w_{L}^{-\frac{\gamma}{1-\gamma}}\right)^{\delta-\delta / \gamma} w_{H}^{1-\delta} w
$$

- For the North's local good: $C_{0}=\theta^{-\theta}(1-\theta)^{\theta-1} W_{H}^{\theta} W_{L}^{1-\theta}$.

- For the South's local good: $c_{0}=w$.

We chose the the industrial good as the numéraire and normalize its unit cost (which equals its price) to $1: C_{I}=1$.

At this point it is useful to come back to the idea of fragmentation. One natural way to measure it is with the ratio $\bar{\ell}_{I} / \bar{L}_{I}$ : the higher it is, the larger is the participation of sourthen wokers in the global value chain. Note that, using the expressions above, it can be expressed as $\left(\frac{\mu}{1-\mu}\right)^{\frac{1}{1-\gamma}} w_{L}^{\frac{1}{1-\gamma}}$. Everything else being kept equal, fragmentation increases with $\mu$ and $\gamma$. Such changes do modify endogenous wages, a fact that has to be captured by the investigation of the equilibrium.

\section{The Equilibrium Equations}

\section{III.1. The Balance-of-Payments' Equation}

Strictly speaking, we have no such thing as a balance-of-payments' equation, since the production of good $I$ is made "nowhere". However, note that consumption of the industrial good $I$ must be financed by the revenue of those workers who are engaged in the production of the industrial good. Therefore, in each country, the value of consumption of $I$ must equal the wage bill of workers engaged in the global value chain. Denoting $Q_{I}$ the total production of good $I$, and remembering that its unit price is normalized to 1 , we obtain, for the North:

$$
\alpha\left(H W_{H}+L W_{L}\right)=Q_{I}\left(\bar{H}_{I} W_{H}+\bar{L}_{I} W_{L}\right)
$$

and similarly, for the South:

$$
\beta w \ell=Q_{I} \bar{\ell}_{I} w
$$


Dividing one equation by the other we eliminate $Q_{I}$, so that:

$$
\frac{\alpha}{\beta}\left(\frac{H}{\ell} w_{H}+\frac{L}{\ell} w_{L}\right)=\frac{\bar{H}_{I}}{\bar{\ell}_{I}} w_{H}+\frac{\bar{L}_{I}}{\bar{\ell}_{I}} w_{L}
$$

Taking into account the above expressions for $\bar{H}_{I}, \bar{L}_{I}$, and $\bar{\ell}_{I}$, we get:

$$
\frac{\alpha}{\beta}\left(\frac{H}{\ell} w_{H}+\frac{L}{\ell} w_{L}\right)=\frac{1-\delta}{\delta}\left(1+\left(\frac{1-\mu}{\mu}\right)^{\frac{1}{1-\gamma}} w_{L}^{-\frac{\gamma}{1-\gamma}}\right)+\left(\frac{\mu}{1-\mu}\right)^{-\frac{1}{1-\gamma}} w_{L}^{-\frac{\gamma}{1-\gamma}}
$$

We rewrite this as:

$$
\frac{\alpha}{\beta}\left(\frac{H}{\ell} w_{H}+\frac{L}{\ell} w_{L}\right)-\frac{1}{\delta}\left(\frac{1-\mu}{\mu}\right)^{\frac{1}{1-\gamma}} w_{L}^{-\frac{\gamma}{1-\gamma}}-\frac{1-\delta}{\delta}=0
$$

a simple relation between $w_{L}$ and $w_{H}$, to which we come back later. We will refer to it as the "Balance-of-payments equation".

Note that this equation expresses the fact that the ratio of consumption of the industrial good between the North and the South equals the ratio of their contribution to the value added of this good.

\section{III.2. The Skilled Labor Market Equilibrium}

Assuming, as above, that the production function for the local good in the North is CobbDouglas, we can write that the total wage bill of skilled workers $H W_{H}$ as:

$$
H W_{H}=((1-\alpha) \theta+\alpha(1-\delta))\left(H W_{H}+L W_{L}\right)+(1-\delta) \beta \ell w
$$

The expression is made up by two parts:

- $(1-\alpha) \theta\left(H W_{H}+L W_{L}\right)$ : the income received from the production of the local good in the North.

- $(1-\delta)\left[\alpha\left(H W_{H}+L W_{L}\right)+\beta l w\right]:$ the income received for the participation in the global value chain of good $I$.

We thus obtain a linear relation between the relative wages $w_{H}=W_{H} / w$ and $w_{L}=W_{L} / w$, namely:

$$
H w_{H}=((1-\alpha) \theta+\alpha(1-\delta))\left(H w_{H}+L w_{L}\right)+(1-\delta) \beta \ell
$$


which can be rewritten as:

$$
w_{H}=\frac{A L}{(1-A) H} w_{L}+\frac{(1-\delta) \beta \ell}{(1-A) H}
$$

with $A=(1-\alpha) \theta+\alpha(1-\delta)$. A belongs to the segment $[\theta, 1-\delta]$.

We will refer to equation (4) as the "Skilled labor market equation".

\section{III.3. The Good I's Market Equilibrium}

The third equation reflects the equilibrium in the international good $I$ 's market, equating its price to the unit cost $P_{I}=C_{I}$. As stated above, we normalize to price to 1 : $P_{I}=1$, and we have $C_{I}=1$ :

$$
\frac{1}{(1-\delta)^{1-\delta} \delta^{\delta}} \mu^{-\delta / \gamma}\left(1+\left(\frac{1-\mu}{\mu}\right)^{\frac{1}{1-\gamma}}\left(w_{L}\right)^{-\frac{\gamma}{1-\gamma}}\right)^{\delta-\delta / \gamma}\left(w_{H}\right)^{1-\delta}=1
$$

We will refer to equation (5) as the "Normalization equation".

\section{III.4. Definition of Equilibrium}

An equilibrium is a vector of wages $\left(W_{L}, W_{H}, w\right)$ that constitutes a solution to the three-equation system formed by equations (3), (4), and (5).

\section{III.5. Solving the System}

Theorem 1. An equilibrium exists and it is unique.

Equation (3) is of the form $w_{H}=f_{1}\left(w_{L}\right)$, with $f_{1}$ decreasing (note that this is independent of the Cobb-Douglas assumption). Equation (4) is of the form $w_{H}=f_{2}\left(w_{L}\right)$ with $f_{2}$ increasing (note again that this is independent of the Cobb-Douglas assumption). So $f_{1}-f_{2}$ is decreasing, and:

$$
\begin{array}{cccc}
w_{L} & 0 & \nearrow & \infty \\
f_{1}\left(w_{L}\right)-f_{2}\left(w_{L}\right) & +\infty & \searrow & -\infty
\end{array}
$$

which implies that there is a single point $w_{L}^{*}$ such that $f_{1}\left(w_{L}^{*}\right)-f_{2}\left(w_{L}^{*}\right)=0$.

FIGURE 1 provides an illustration of the equilibrium in the $\left(w_{h}, w_{l}\right)$ space, which is represented by point $\mathrm{E}$. 


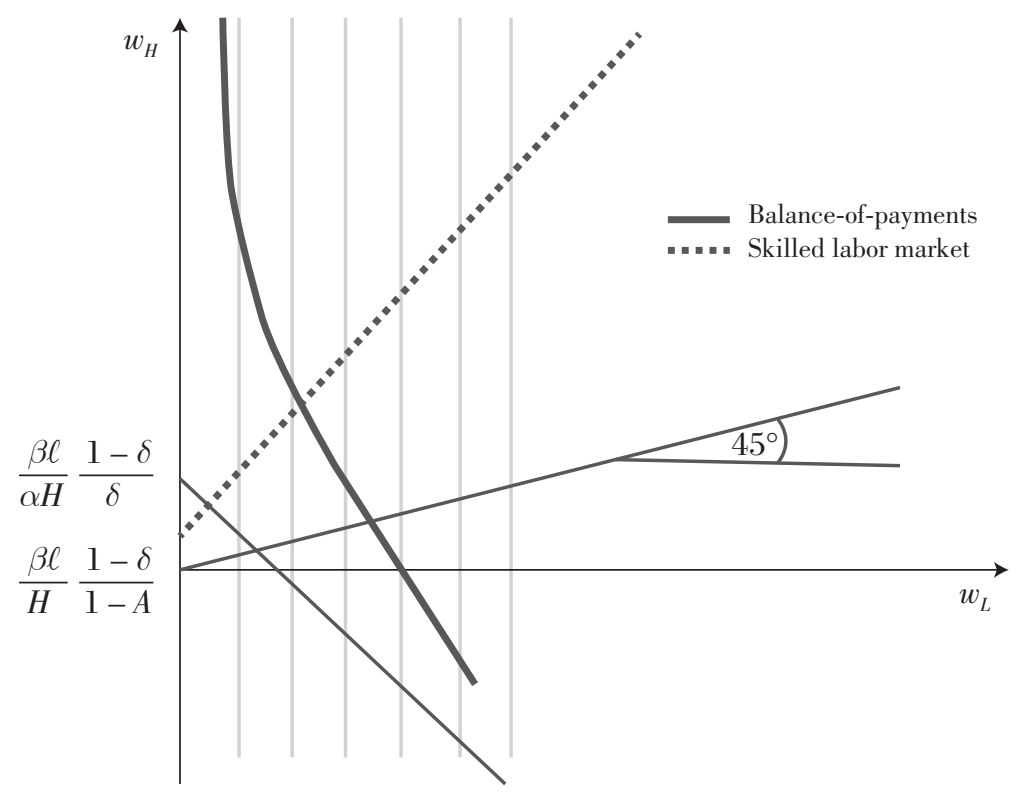

Figure 1. - Equilibrium

After solving for $\left(w_{L}^{*}, w_{H}^{*}\right)$ we can use normalization equality $C_{I}=1$ to obtain $w^{*}$. Finally, absolute wages can then be recovered using the fact that $W_{H}^{*}=w_{H}^{*} w^{*}$ and $W_{L}^{*}=w_{L}^{*} w^{*}$.

This completes the solution of the model's equilibrium. We next study two important properties of the equilibrium.

\section{III.6. Equilibrium Properties}

To go further into the study of the equilibrium, it proves useful to write equations (3), (4), and (5) in a more compact fashion. Respectively:

$$
\begin{array}{r}
\frac{\alpha}{\beta \ell}\left(H w_{H}+L w_{L}\right)-\frac{1}{\delta} m^{-g-1} w_{L}^{-g}-\frac{1-\delta}{\delta}=0 \\
(1-A) H w_{H}-A L w_{L}-(1-\delta) \beta \ell=0 \\
\Delta\left(\frac{m}{m+1}\right)^{-\delta\left(1+\frac{1}{g}\right)}\left(1+m^{-g-1} w_{L}^{-g}\right)^{-\frac{\delta}{g}} w_{H}^{1-\delta} w=1
\end{array}
$$

with $g=\frac{\gamma}{1-\gamma}, m=\frac{\mu}{1-\mu}$ and $\Delta=\frac{1}{(1-\delta)^{1-\delta} \delta^{\delta}}$ 
Note that $(g, m, \Delta)$ are all strictly positive. $g(\gamma)$ is monotonically increasing in $\gamma$ and $m(\mu)$ is monotonically increasing in $\mu$. We can write equation (6) in the form:

$$
w_{H}=\frac{\beta \ell}{\alpha H}\left[\frac{1}{\delta} m^{-g-1} w_{L}^{-g}+\frac{1-\delta}{\delta}\right]-\frac{L}{H} w_{L}
$$

The right-hand side, as noted above, is a strictly decreasing function of $w_{L}>0$. Its derivative is:

$$
-\frac{L}{H}-g \frac{\beta \ell}{\alpha H}\left[\frac{1}{\delta} m^{-g-1} w_{L}^{-g-1}\right]
$$

Write equation (7) in the form:

$$
w_{H}=\frac{A L}{(1-A) H} w_{L}+\frac{(1-\delta) \beta \ell}{(1-A) H}
$$

The following proposition gives two results concerning the equilibrium, in line with our introductory presentation. The first one gives a simple and weak condition on the relative populations of skilled and unskilled workers in the North, which will imply that, in equilibrium, unskilled workers have a lower wage than the skilled ones and which is true in all numerical simulations (available upon request). The second one, $w_{L}^{*}>(1 / m)$, states that, in equilibrium, the wage of the unskilled workers in North relative to the unskilled workers' wage in the South is higher than what is implied by their apparent relative productivity in the production of the industrial good. This relies on a weak condition concerning the number of workers in the South.

Proposition 1. The following statements hold:

1. If $\frac{L}{H}>\frac{1-A}{A}$, then $w_{H}^{*}>w_{L}^{*}$.

2. If $m<1$ and $\beta \ell>L$, then $w_{L}^{*}>1 / m$.

Proof. See the Appendix.

Point 1 ) is obvious, since the affine function defined by (10) has slope greater than 1 . Regarding point 2), we note that $m=\frac{\mu}{1-\mu}$ is an increasing function of $\mu$, and that the condition $m<1 / \delta$ limits attention to the case where $m$ is either smaller than 1 , which we have in mind for this setting, or not too much larger.

From now on, we assume $m<1$ (which is equivalent to $\mu<1 / 2$ ). 


\section{Comparative Statics}

We are now able to proceed to the core of our analysis, i.e. the comparative statics.

\section{IV.1. Dependence on $\alpha$}

An increase in $\alpha$ reflects a higher level of consumption of the industrial good by northern workers. It implies a downward shift of equation (9). The change in equation (10) depends on other parameters:

- If $\theta<1-\delta$, an increase in $\alpha$ increases $A$ and $\frac{1}{1-A}$ and implies that $d w_{L}<0$, and $d\left(w_{H} / w_{L}\right)>0$.

- If $\theta>>1-\delta, d w_{H}$ is negative, and $d\left(w_{H} / w_{L}\right)<0$.

The result is expressed in the following Lemma:

Lemma 3. If $d \alpha>0$, then

- If $\theta \leq 1-\delta$, then $d w_{L}<0$, and $d\left(w_{H} / w_{L}\right)>0$.

- If $\theta>>1-\delta$, then $d w_{H}<0$ and $d\left(w_{H} / w_{L}\right)<0$.

IV.2. Dependence on $\beta$

An increase in $\beta$ implies a higher consumption of the industrial goods by southern workers. It has two effects. It shifts up the curve defined by (9), and shifts up the line defined by (10), respectively by:

$$
\begin{aligned}
d w_{H}^{\prime \prime} & =\frac{\ell}{\alpha H}\left[\frac{1}{\delta} m^{-g-1} w_{L}^{-g}+\frac{1-\delta}{\delta}\right] d \beta \\
d w_{H}^{\prime} & =\frac{(1-\delta) \ell}{(1-A) H} d \beta
\end{aligned}
$$

Note that since $\alpha \delta<1-A$, we have $d w_{H}^{\prime \prime}>d w_{H}^{\prime}$. Geometrically, it is obvious that the new intersection is such that $d w_{H}>0$, but also $d w_{L}>0$, and the price normalization condition implies that $d w<0$.

What about $d\left(w_{H} / w_{L}\right)$ ? The answer is not obvious and requires some computations, which are provided in the appendix. It is clear that $d W_{H}$ has to be positive. The fact that $d W_{L}>0$ results from additional computations.

We sum up:

Lemma 4. If $d \beta>0$, then $d w_{H}>0, d w_{L}>0$ and $d w<0$.

It is also the case that $d\left(w_{H} / w_{L}\right)>0, d W_{H}>0$ and $d W_{L}>0$. 


\section{IV.3. Dependence on $m$}

The parameter $m$ gives the weight of the South's unskilled workers in the global value chain. The curve (9) shifts down in the relevant area and the line (10) is unaffected. Then, it is geometrically straightforward that $d w_{H}<0, d w_{L}<0$, and from the price normalization condition, it follows that $d w>0$. It is also clear that $d\left(w_{H} / w_{L}\right)>0$. In terms of absolute wages, it follows that $d W_{L}<0$.

Lemma 5. If $d m>0$, then $d w_{H}<0, d w_{L}<0$, and $d w>0$.

It is also the case that $d\left(w_{H} / w_{L}\right)>0$ and $d W_{L}<0$.

In terms of absolute wages, it is intuitively plausible that $d W_{H}>0$. This is not generally true, but the situation obtains in our numerical computations whenever $\beta$ becomes high enough.

\section{IV.4. Dependence on $g$}

An increase in the synthetic parameter $g$ implies an increase in $\gamma$, which represents the elasticity of substitution between North's and South's unskilled workers in the global value chain. Geometrically, when $g$ increases, it lowers the curve (9) if $m w_{L}>1$, while leaving equation (10) unaffected.

Lemma 6. If $d g>0$, then $d w_{H}<0, d w_{L}<0$, and $d w>0$.

We also have $d\left(w_{H} / w_{L}\right)>0$.

\section{IV.5. Dependence on $\delta$}

A decrease in $\delta$ (i.e. an increase in $(1-\delta)$ ), implying a lower weight of skilled workers in the production of good $I$, increases $A$ (and $\frac{A}{1-A}$ ), shifting up the curve (9). Then the following obtains.

Lemma 7. If $\delta$ decreases, then $d w_{H}>0$.

One can also prove $d w_{L}>0$, and $d\left(w_{H} / w_{L}\right)>0$, unless $L / l$ is small, see the working paper version.

\section{IV.6. Dependence on $\theta$}

An increase in $\theta$ implies a higher share of unskilled workers in the production of the North's local good. It increases $A$ and leaves the curve (9) unaffected.

Lemma 8. If $d \theta>0$, then $d w_{H}>0, d w_{L}<0$, and $d\left(w_{H} / w_{L}\right)>0$. 


\section{IV.7. Summary}

Consider the forces behind globalization. In our model, they are intuitively reflected by an increase in $(\mu, \gamma)$, associated with the relative productivity and substitutability of South's labor, and also with an increase in $(\beta, \alpha)$, the income shares of the industrial good. We find:

A) Whenever there is an increase in the forces of globalization, through the competitiveness of the South, i.e whenever $(\mu, \gamma)$ increase, $d\left(w_{H} / w_{L}\right)>0$ obtains: i.e. there is a deterioration of the situation of the North low skilled workers relatively to the North high skilled. Indeed, in both cases $d w>0$ and $d W_{L}<0$.

B) $d\left(w_{H} / w_{L}\right)>0$ also obtains when the South's income share of the industrial good, $\beta$, increases. For the North, an increase in $\alpha$, the sign of $d\left(w_{H} / w_{L}\right)$ is the same sign of $(1-\delta-\theta)$.

C) The same $d\left(w_{H} / w_{L}\right)>0$ is true whenever $1-\delta$ increases, such a change being possibly interpreted as the effect of increasing innovation triggered by globalization.

D) The result $d\left(w_{H} / w_{L}\right)>0$ still holds whenever $\theta$ increases (although such a move does not a priori reflect the forces of globalization).

\section{A Simple Quantitative Analysis}

In this section we use our model to perform a simple quantitative analysis. The objective is not to provide a fully-fledged calibration, but rather to help grasping the plausibility of our model when contrasted with real-world data.

We base this section on the empirical analysis of Timmer, M., et al. [2014], who provide an estimation of value added shares of different productive factors within global value chains (henceforth GVC). An interesting point in their analysis is that they are able to calculate value-added shares within geographical regions. They divide the world in two groups, placing "high income" countries on one side and the rest in a second group. We will identify "high income" countries with the North, and the second group, with the South. ${ }^{5}$ We use 1995 as our benchmark year.

We now discuss how we obtain the parameter values. First, notice that, in our simple model, we have assumed that the production function for the internationally traded good $Q_{I}$ uses only labor. In order to account for the share of capital we proceed as follows. For the North, we multiply the value added by each type of labor by a factor $\frac{1}{1-z}$, where $z$ is the value added share of capital. This method then allocates the capital stock to each type of labor, allocating more per-capita capital to skilled workers (i.e. those with higher wages). For the South, we follow the model and consider that it has only one production

5. The countries listed as high income are the following: Australia, Canada, and the United States; Japan, South Korea, and Taiwan; and all 15 countries that joined the European Union before 2004. 
factor, which accounts for $100 \%$ of South's value added of $Q_{I}$. We recalculate value added shares using the data in TABLE III in Timmer, M., et al. [2014]:

Table I. - Value Added Shares in Global Value Chains

\begin{tabular}{cccc}
\hline \hline & $H$ & $L$ & $\ell$ \\
\hline 1995 & $19 \%$ & $54 \%$ & $27 \%$ \\
2008 & $20 \%$ & $36 \%$ & $44 \%$ \\
\hline
\end{tabular}

For factor endowments we use the data provided in the Socio-Economic Accounts of the World Input-Output Database (WIOD, available at www.wiod.org). We use hours worked by labor type, and adjust the size of workforces to account for capital in the manner described above. We normalize $l=200$ and set $H=10$ and $L=36$ to account for the relative sizes of workforces in the North and the South.

Equation (1) provides a relationship between the North's consumption of the industrial good $Q_{I}$ and the revenue obtained by workers in the North from the production of that good. Similarly for equation (2) that concerns the South. This means that we can back up $\alpha$ and $\beta$ using data on the share of value added of $Q_{I}$ produced in each region, as well as each region's GDP. ${ }^{6}$ Timmer et al. estimate that GVC value added accounted for $23 \%$ of the World's GDP in 1995. That year, the GDP from the North and that of the South accounted for 77\% and 23\% of World GDP (Source: World Bank Development Indicators' database). Using this information it is easy to show that equations (1) and (2) imply $\alpha=0,21$ and $\beta=0,26$ respectively.

We set $\theta=0,6$, calculated using the average share of skilled labor in total compensation in the North in non-tradable industries for the high-income countries (Source: WIOD). We set $\delta=0,81$ to match the share of value added by skilled labor from TABLE I.

Parameters $(\gamma, \mu)$ are central to our analysis, as they determine the level of international fragmentation. The parameter $\gamma$ governs the elasticity of substitution between North's and South's unskilled workers in the global value chain, which is given by $\sigma$ : we have $\gamma=\frac{\sigma-1}{\sigma}$. For our tentative experiment, we set $\gamma=0.75$ which corresponds to $\sigma=4$, following a somewhat bold interpretation of (a value close to) the mean estimate for the US (4.17) provided by BRoDA, C., et al. [2006] in their estimations of trade elasticities for intermediate inputs. ${ }^{7}$. We take $\mu$ as a free parameter, choosing the value required to match the shares in TABLE $\mathrm{I}$, which is $\mu=0.14^{8}$.

6. Specifically we use $\alpha=\frac{Q_{I}\left(\bar{H}_{I} W_{H}+\bar{L}_{I} W_{L}\right)}{\left(H W_{H}+L W_{L}\right)}$ and $\beta=\frac{Q_{I} \bar{\ell}_{I} w}{w \ell}$.

7. The estimates in BRoDA, C. et al. are obtained from data covering 1995-2003. Given the lack of more recent data, we use the same value for 1995 and 2008.

8. Similar results obtain using different combinations of the pair $(\gamma, \mu)$, for example the following: $(0,4 ; 0,2),(0,5 ; 0,19)$. It is easy to see that both higher $\gamma$ and $\mu$ imply higher equilibrium values of $w$ and 
TABLE II summarizes the parameter values with which our model exactly replicates the 1995 factor shares of TABLE I, as well as the observed division of world's GDP between the North and the South. We repeat the exercise for 2008, using the parameter values given in TABLE II. ${ }^{9}$

TABLE II. - Parameter Values

\begin{tabular}{cccccccccc}
\hline \hline & $\alpha$ & $\beta$ & $\theta$ & $\delta$ & $\gamma$ & $\mu$ & H & L & $\ell$ \\
\hline 1995 & 0,21 & 0,26 & 0,6 & 0,81 & 0,75 & 0,14 & 10 & 36 & 200 \\
2008 & 0,13 & 0,18 & 0,6 & 0,80 & 0,75 & 0,23 & 12 & 29 & 200 \\
\hline
\end{tabular}

We can now discuss what insights our model can provide to understand the changes shown in TABLE I. The main message arising from the comparison of the numbers for 1995 and 2008 is that, quantitatively, the increase in the share of the South's unskilled workers, from $27 \%$ to $44 \%$, is driven exclusively by the increase in the fragmentation parameter $\mu$, which changes from 0.14 to 0.23 , i.e. a $64 \%$ increase. There is no straightforward empirical proxy for $\mu$ unfortunately. ${ }^{10}$ Still, our simple model generates patterns which are quite reasonable in light of the real-world data.

In line with the comparative statics presented in the previous section, the increase in the value-added share of South's workers arising from higher $\mu$ is accompanied with a reduction the wages of workers in the North, both in absolute terms and with respect to that of workers in the South. Wage inequalities in the North increase with the participation of the South in the global value chain. These effects of globalization have been well documented (see e.g. Harrison A., et al. [2011]).

The impact of changes in consumption patterns, as given by $\alpha$ and $\beta$, modify wages in line with the predictions of SECTION IV, but their impact on value-added shares is small. Changes in factor endowments, namely the increase in the relative size of the South and the increase in the relative endowment of skilled workers in the North, are relatively minor in size and have little explanatory power for the factor shares. The numerical version of the model therefore points to the changes in the production function of global value chains as the main driver of the evolution of wages and the distribution of global value added.

$\overline{\bar{\ell}_{I}}$, which in turn generates a larger participation of the South both in the production of $Q_{i}$ and in global GDP. Thus, larger values of $\mu$ require lower values for $\gamma$ and viceversa.

9. In 2008, the South's share of World's GDP increased to 37\%. Value-added in global value chains accounted for 15\% of World's GDP. Using equations (1) and (2) with these values we obtain the values for $\alpha$ and $\beta$ provided in TABLE II.

10. There is no trade in a strict sense in the model. However, the GVC's value-added originating in each country can be thought of as exports. The connection between GVC value-added and $\gamma, \mu, \delta$ (simple in the case with $\gamma$ close to zero), can serve to provide a proxy to exports of the South (for which it is most likely that gross trade flows are larger than value-added terms) Such an analysis provide some ligth on $\mu$. (see discussion paper) 


\title{
VI. Conclusion
}

We have provided a simple, perhaps too simple model, which allows us to exhibit more clearly the respective role of different forces relating to our present globalization, as factors of the inequalities increases in the North. The conclusions may look unsurprising given the modelling input. The mechanics of the model differs significantly from the standard Heckscher-Ohlin story and its actual mechanics is far from straightforward. Two equations govern equilibrium, the second one expresses in a rather intuitive way the determination of the wage of skilled labor in the North. The first one expresses the equality of the ratio of the contribution of the North and the South in the production of the industrial good with the ratio of its consumption. We are aware that a better intuition on this equality is a prerequisite to the generalization of the model, left for future research. We believe that the comparison of the theoretical perspectives with the stylised facts concerning the evolution of the world trade, as measured in the work of TILLMER et al., supports (or at least illustrates) the theoretical story developed here. Again, although the context differs much of the context of the seventies, eighties or nineties, in which Malinvaud developed his views on wages, we hope that our attempt at shedding light on the present forces in the labor market, echoes Malinvaud's example and lessons.

\section{ACKNOWLEDGEMENTS}

We are grateful to Camilo Carluccio for helpful discussions. All remaining errors are our own.

\author{
Correspondence: \\ Juan Carluccio \\ Banque de France \\ 46-2401 DGEI-DEMS-SAMIC \\ 31 Croix des Petits Champs \\ 75049 PARIS CEDEX 01 \\ E-mail: ?????????? \\ Ivar Ekeland \\ CEREMADE et Institut de Finance \\ Université Paris-Dauphine \\ 75775 PARIS CEDEX 16 \\ E-mail: ?????????? \\ Roger Guesnerie \\ Collège de France \\ 3 rue d'Ulm \\ 75003 PARIS \\ E-mail: ??????????
}




\section{Appendix}

\section{A. Proof of Lemma 1}

Minimizing $W_{L} L_{I}+W_{H} H_{I}+w \ell_{I}$ under the constraint:

$$
(1-\delta) \ln H_{I}+\frac{\delta}{\gamma} \ln \left(\mu \ell_{I}^{\gamma}+(1-\mu) L_{I}^{\gamma}\right)=0
$$

we find:

$$
\begin{aligned}
W_{H} & =\lambda \frac{1-\delta}{H_{I}} \\
W_{L} & =\lambda \delta \frac{(1-\mu) L_{I}^{\gamma-1}}{\mu \ell_{I}^{\gamma}+(1-\mu) L_{I}^{\gamma}} \\
w & =\lambda \delta \frac{\mu \ell_{I}^{\gamma-1}}{\mu \ell_{I}^{\gamma}+(1-\mu) L_{I}^{\gamma}}
\end{aligned}
$$

Hence:

$$
\begin{aligned}
\frac{W_{L}}{w} & =w_{L}=\frac{(1-\mu) L_{I}^{\gamma-1}}{\mu \ell_{I}^{\gamma-1}} \\
\frac{W_{H}}{w} & =w_{H}=\frac{1-\delta}{\delta} \frac{\mu \ell_{I}^{\gamma}+(1-\mu) L_{I}^{\gamma}}{\mu H_{I} \ell_{I}^{\gamma-1}}
\end{aligned}
$$

It follows that:

$$
\begin{aligned}
L_{I} & =\left(\frac{\mu}{1-\mu} w_{L}\right)^{-\frac{1}{1-\gamma}} \ell_{I} \\
H_{I} & =\frac{1-\delta}{\delta} \frac{1}{w_{H}}\left(\frac{\mu \ell_{I}^{\gamma}+(1-\mu) L_{I}^{\gamma}}{\mu \ell_{I}^{\gamma-1}}\right) \\
& =\frac{1-\delta}{\delta} \frac{1}{w_{H}}\left(1+\frac{1-\mu}{\mu}\left(\frac{L_{I}}{\ell_{I}}\right)^{\gamma}\right) \ell_{I} \\
& =\frac{1-\delta}{\delta} \frac{1}{w_{H}}\left(1+\left(\frac{1-\mu}{\mu}\right)^{\frac{1}{1-\gamma}} w_{L}^{-\frac{\gamma}{1-\gamma}}\right) \ell_{I}
\end{aligned}
$$


The quantity $\bar{\ell}_{I}$ needed to produce one unit is given by:

$$
\begin{aligned}
1 & =\left(\mu \bar{\ell}_{I}^{\gamma}+(1-\mu) \bar{L}_{I}^{\gamma}\right)^{\delta / \gamma} \bar{H}_{I}^{1-\delta} \\
& =\mu^{\delta / \gamma}\left(1+\frac{1-\mu}{\mu}\left(\frac{\bar{L}_{I}}{\bar{\ell}_{I}}\right)^{\gamma}\right)^{\delta / \gamma} \ell_{I}^{\delta} \bar{H}_{I}^{1-\delta} \\
& =\mu^{\delta / \gamma}\left(1+\frac{1-\mu}{\mu}\left(\frac{\bar{L}_{I}}{\bar{\ell}_{I}}\right)^{\gamma}\right)^{\delta / \gamma} \bar{\ell}_{I}^{\delta}\left(\frac{1-\delta}{\delta}\right)^{1-\delta} \frac{1}{w_{H}^{1-\delta}}\left(1+\frac{1-\mu}{\mu}\left(\frac{\bar{L}_{I}}{\bar{\ell}_{I}}\right)^{\gamma}\right)^{1-\delta} \bar{\ell}_{I}^{1-\delta} \\
& =\mu^{\delta / \gamma}\left(\frac{1-\delta}{\delta}\right)^{1-\delta} \frac{1}{w_{H}^{1-\delta}}\left(1+\left(\frac{1-\mu}{\mu}\right)^{\frac{1}{1-\gamma}} w_{L}^{-\frac{\gamma}{1-\gamma}}\right)^{1-\delta+\delta / \gamma} \bar{\ell}_{I}^{1}
\end{aligned}
$$

Hence $\bar{\ell}_{I}$. Substituting, we get $\bar{H}_{I}$ and $\bar{L}_{I}$

\section{B. Proof of Lemma 4}

Note that the slope of the curve $(9)$ in $w_{H}(*, \beta)+d w_{H}^{\prime}, w_{L}(*, \beta)$, is approximately:

$$
-\frac{L}{H}-g \frac{\beta \ell}{\alpha H}\left[\frac{1}{\delta} m^{-g-1} w_{L}^{-g-1}\right]
$$

so that at the intersection with line 8 in $w_{L}(*, \beta)+d \nu,\left(d w_{L}=d \nu\right)$

$$
\begin{aligned}
& \frac{(1-\delta) \ell(d \beta)}{(1-A) H}+\left(\frac{A}{1-A} \frac{L}{H}\right) d \nu=\frac{\ell}{\alpha H}\left[\frac{1}{\delta} m^{-g-1} w_{L}^{-g}+\frac{1-\delta}{\delta}\right](d \beta) \\
& -\left(\frac{L}{H}+g \frac{\beta \ell}{\alpha H}\left[\frac{1}{\delta} m^{-g-1} w_{L}^{-g-1}\right]\right) d \nu \\
& {\left[\frac{\alpha}{1-A}\left(\frac{L}{\alpha H}\right)+g \frac{\beta \ell}{\alpha H}\left(\frac{1}{\delta} m^{-g-1} w_{L}^{-g-1}\right)\right] d \nu} \\
& =\frac{\ell}{\alpha H}\left[\frac{1}{\delta} m^{-g-1} w_{L}^{-g}+\frac{1-\delta}{\delta}-\frac{(1-\delta) \alpha}{(1-A)}\right](d \beta)
\end{aligned}
$$


Multiplying by $\frac{\alpha H}{\ell}$ :

$\left[\frac{\alpha}{1-A}\left(\frac{L}{l}\right)+g \beta \frac{1}{\delta} m^{-g-1} w_{L}^{-g-1}\right] d \nu=\left[\frac{1}{\delta} m^{-g-1} w_{L}^{-g}+\frac{1-\delta}{\delta}-\frac{(1-\delta) \alpha}{(1-A)}\right](d \beta)$

Remembering that:

$$
\frac{\alpha}{\beta \ell}\left(H w_{H}+L w_{L}\right)-\frac{1}{\delta} m^{-g-1} w_{L}^{-g}-\frac{1-\delta}{\delta}=0
$$

so that:

$$
\left[\frac{\alpha}{1-A}\left(\frac{L}{l}\right)+g \beta \frac{1}{\delta} m^{-g-1} w_{L}^{-g-1}\right] d \nu=\left[\frac{\alpha}{\beta \ell}\left(H w_{H}+L w_{L}\right)-\frac{(1-\delta) \alpha}{(1-A)}\right](d \beta)
$$

As:

$$
\begin{gathered}
w_{H}=\frac{A L}{(1-A) H} w_{L}+\frac{(1-\delta) \beta \ell}{(1-A) H} \\
{\left[\frac{\alpha}{\beta \ell}\left(H w_{H}+L w_{L}\right)-\frac{(1-\delta) \alpha}{(1-A)}\right]=\frac{\alpha}{1-A} \frac{L w_{L}}{\beta \ell}}
\end{gathered}
$$

we get:

$$
\left[\alpha L+g \beta l(1-A) \frac{1}{\delta} m^{-g-1} w_{L}^{-g-1}\right] d \nu=\left[\alpha \frac{L w_{L}}{\beta}\right](d \beta)
$$

We now have to compare the slope $\frac{w H}{w_{L}}$ at the initial point $(*)$ (forget $(*)$ now)

$$
\frac{(1-\delta) \ell \beta}{(1-A) H w_{L}}+\frac{A}{1-A} \frac{L}{H}
$$

to the slope of the line connecting the new equilibrium to the initial one, i.e

$$
d w_{H}^{\prime} / d \nu+\frac{A}{1-A} \frac{L}{H}
$$


i.e

$$
\frac{(1-\delta) \ell(d \beta / d \nu)}{(1-A) H}+\frac{A}{1-A} \frac{L}{H}
$$

It is enough to compare:

$$
\frac{(1-\delta) \ell(d \beta / d \nu)}{(1-A) H}
$$

with

$$
(d \beta / d \nu)=\frac{\left[\alpha L+g \beta l(1-A) \frac{1}{\delta} m^{-g-1} w_{L}^{-g-1}\right]}{\left[\alpha \frac{L w_{L}}{\beta}\right]}
$$

$w_{L}>1$

$$
(d \beta / d \nu)>\frac{\beta}{\left[w_{L}\right]}
$$

i.e

$$
\frac{[\alpha L+g \beta l(1-A)]\left[\frac{1}{\delta} m^{-g-1} w_{L}^{-g-1}\right]}{[\alpha L]}>1
$$

which is always true.

\section{Proof of Proposition 1}

The condition $w_{L}^{*}>(1 / m)$ holds true iff the value of the right-hand side for $w_{L}=1 / m$ is higher in equation (9) than in equation (10), namely:

$$
\frac{\beta \ell}{\alpha H}\left[\frac{1}{\delta} m^{-g-1} m^{+g}+\frac{1-\delta}{\delta}\right]-\frac{L}{H} m^{-1}>\frac{A L}{(1-A) H} m^{-1}+\frac{(1-\delta) \beta \ell}{(1-A) H}
$$

or:

$$
\frac{1}{m} \frac{\beta \ell}{\alpha \delta}\left[1-\frac{L}{(1-A)} \frac{\alpha \delta}{\beta \ell}\right]>-\frac{\beta \ell}{\alpha \delta}(1-\delta)+\frac{(1-\delta) \beta \ell}{(1-A)}>
$$


If $m<1$, then a sufficient condition is:

$$
\left[1-\frac{L}{(1-A)} \frac{\alpha \delta}{\beta \ell}\right]>(1-\delta]\left[\frac{\alpha \delta}{(1-A)}-1\right]
$$

At this point one should note that $A<1$ implies that $\alpha \delta<1-A$. So the righthand side is negative. Substituting $\beta \ell>L$ in the left-hand side, we find that it is positive. So the inequality holds true, and the result is proved.

\section{References}

Acemoglu, D., G. Gancia, and F. Zilibotti (2015): "Offshoring and Directed Technical Change", American Economic Journal: Macroeconomics, 7(3), 84-122.

Antràs, P. (2016): "Global Production: Firms, Contracts and Trade Structure", Princeton University Press.

Bourguignon, F., and R. Guesnerie (1996): "Mondialisation : moins d'inégalités entre les nations, plus d'inégalités au sein des nations ?"

Broda, C., J. Greenfield, and D. Weinstein (2006): "From Groundnuts to Globalization: A Structural Estimate of Trade and Growth", NBER Working Paper No. 12512.

Carluccio, J., A. Cunat, H. Fadinger, and C. Fons-Rosen (2016): “Offshoring and Skillupgrading in French Manufacturing: A Heckscher-Ohlin-Melitz View”, mimeo.

Costinot, A., and J. Vogel (2010): "Matching and Inequality in the world economy", Journal of Political Economy, 118, 747-86.

Ebenstein, A., A. Harrison, and M. Mc Millan (2014): "Why are American Workers Getting Poorer? China, Trade and Offshoring", mimeo.

Freeman, R. (1995): “Are Your Wages Set in Beijing?” Journal of Economic Perspectives, 9(3), 15-32.

Grossman, G., and E. Rossi-Hansberg (2008): "Trading Tasks: A Simple Theory of Offshoring", American Economic Review, 98(5), 1978-97.

Harrison A., J. McLaren, and M. McMillan (2011): “Trade and Inequality", Annual Review of Economics, 3, 261-89.

Helpman, E. (1984): “A Simple Theory of International Trade With Multinational Corporations", Journal of Political Economy, 92(3), 451-471.

Malinvaud, E. (1953): "Capital Accumulation and Efficient Allocatiuon of Ressources", Econometrica, 21(2), 233-238, Econometrica. 
Malinvaud, E. (1980): "Profitability and Unemployment", Cambridge University Press, Cambridge.

Malinvaud, E. (1981 et 1982): “Théorie Macroéconomique”, Dunod, Paris.

Malinvaud, E. (1983): "Essais sur la théorie du chômage”, Calmann-Lévy, Paris.

Malinvaud, E. (1984): “Mass Unemployment”, Basil Blackwell, Oxford.

Malinvaud, E. (1986): "Reflecting on the Theory of Capital and Growth", In: Oxford Economic Papers. Band 38, 367-85.

Malinvaud, E. (1987): "Capital productif, incertitudes et profitabilité", Annales d'Économie et de Statistiques, 5, janvier-mars, 1-36.

Malinvaud, E. (1991): “A Medium Term Employment Equilibrum”, In: W. Barnett and al. Equilibrum Theory and Applications. Cambridge University Press, Cambridge, 319-337.

Malinvaud, E. (1991): "Voies de la recherche macroéconomique", Odile Jacob.

Malinvaud, E. (1994): “Diagnosing Unemployment”, Cambridge University Press, Cambridge.

Rodrik, D. (1997): “Has Globalisation Gone Too Far?”, Washington DC, Institute for International Economics.

Thoenig, M., and T. Verdier (2003): “A Theory of Defensive Skil-Biased Innovation and Globalization", American Economic Review, 93(3), 709-28.

Timmer, M., A. A. Erumban, B. Los, R. Stehrer, and G. de Vries (2014): “Slicing Up Global Chains", Journal of Economic Perspectives, 28(2), 99-118. 